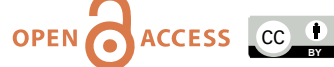

doi: 10.31729/jnma.6511

\title{
A Paraurethral Vaginal Mass in Rural Setting: A Case Report
}

\author{
Niresh Thapa, ${ }^{1}$ Subi Basnyat, ${ }^{2}$ Dilsahi Roka ${ }^{2}$ \\ 'Department of General Practice and Emergency Medicine, Karnali Academy of Health Sciences, Jumla, Nepal, \\ ${ }^{2}$ Department of Obstetrics and Gynecology, Karnali Academy of Health Sciences, Jumla, Nepal.
}

\begin{abstract}
Paraurethral vaginal leiomyoma is the infrequent case to be described. Approximately 300 cases have been described so far. Imaging modalities aid in identifying the morphological, structural characteristics of the mass and its relationship to the surrounding structures. Thirty-six years old married women presented with a vulvar mass of $(3 \times 5) \mathrm{cm}^{2}$. Her associated complaints were left shift of the urinary stream and dyspareunia. Ultrasonography and cystography revealed a mass with no relationship with bladder or uterine structure. Surgical excision was performed. The histopathological report confirmed the diagnosis of paraurethral vaginal leiomyoma. Surgical excision is the treatment of choice and diagnosis is confirmed by histopathological examination.
\end{abstract}

Keywords: leiomyoma; rare diseases; rural health services.

\section{INTRODUCTION}

A variety of pathologies from benign to malignant conditions like urethro-cystocele, Gartner's duct cyst, Skene duct cyst, urethral diverticulum, Bartholin gland cyst or vaginal malignancy should be considered in a vaginal wall mass. ${ }^{1}$ Vaginal and paraurethral leiomyoma are rare conditions to observe and difficult to diagnose at the time of presentation. Preoperatively ultrasonography (USG) and magnetic resonance imaging $(\mathrm{MRI})$ are indicated to establish morphology, location, and relationship of mass to the adjacent structures. ${ }^{2}$ Surgical excision is the treatment of choice. $^{3}$ Histopathological examination (HPE) is the gold standard for diagnosis. ${ }^{4}$ We report a case of thirty-six years old married, women presented with vulvar mass.

\section{CASE REPORT}

Thirty-six years old married, parity three women presented with vulvar mass which had gradually increased in a year. She had a history of dyspareunia and a left shift of the urinary stream. There was no significant medical or surgical past history. Clinical examination revealed well defined, firm, solitary mass of $(3 \times 5) \mathrm{cm}^{2}$. Vaginal epithelium over the mass had no rugosity and urethral meatus was shifted laterally to left (Figure 1).

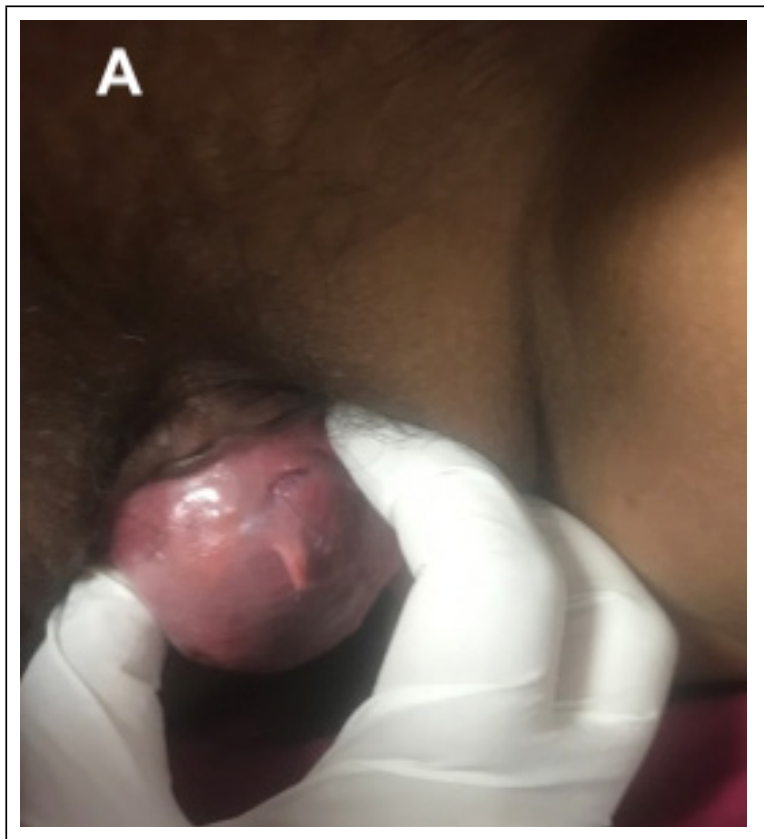

Figure 1. Preoperative $(3 \times 5) \mathrm{cm}^{2}$ anterior vaginal mass.

USG revealed homogenous, hypoechoic mass with increased vascularity and no arising of the mass from any part of the bladder or uterine structure.

Correspondence: Dr. Niresh Thapa, Department of General Practice and Emergency Medicine, Karnali Academy of Health Sciences, Jumla, Nepal. Email: niresht@hotmail. com, Phone: +977-9857028261 
Cystography revealed no identification of the origin of mass from the bladder and urethral structure. The patient and her husband were counselled for surgical removal of mass with the provisional diagnosis of vaginal leiomyoma. Informed consent was obtained for the procedure.

A midline surgical incision was performed under spinal anaesthesia. A solid mass was encapsulated with no connection between the mass and the urethra (Figure 2).

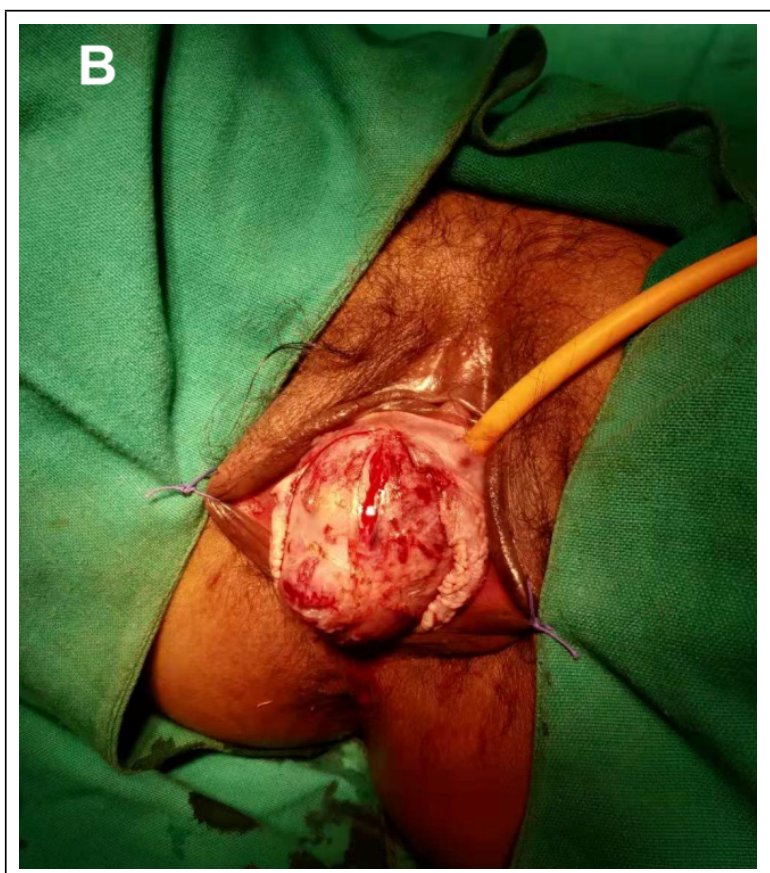

Figure 2. Intraoperative anterior vaginal mass.

Sharp and blunt dissection was done to enucleate the mass (Figure 3). The wall was closed in two layers. Foley's catheter was inserted throughout the procedure. The patient was discharged in three days with no urinary complain. The patient was followed up after two weeks with a HPE report which was vaginal leiomyoma.

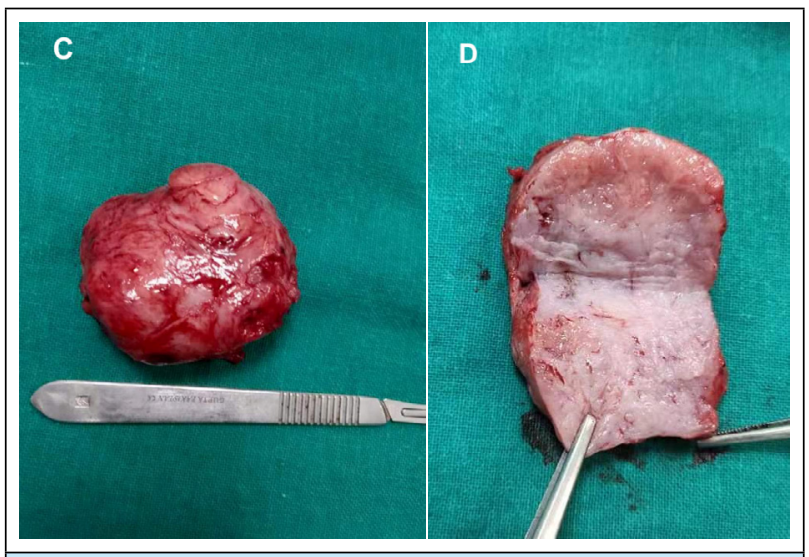

Figure 3. Enucleated and cut section of vaginal mass.

\section{DISCUSSION}

Vaginal paraurethral leiomyoma is a rare benign mesenchymal tumor. Since its first description in 1733 by Denys de Leyden approximately 300 cases, ${ }^{5}$ have been reported with none from Nepal. The vaginal tumor is common in the reproductive age group between 35-50 years. ${ }^{6}$ The patient in our case was of age 36 years and ovarian hormone could stimulate the development of leiomyoma in this age group. ${ }^{7}$

Depending on the anatomic location and size of the mass the symptoms can vary from being asymptomatic to other symptoms like dyspareunia, dysuria, urinary tract infection, and obstructive voiding symptoms. ${ }^{6,8}$ The case presented to us with dyspareunia with no particular urinary complaints. Vagina leiomyoma indeed has been termed female prostate. ${ }^{9}$ Ischemia following a contraction of the smooth muscles could lead to pain, ${ }^{10}$ this could be the reason patient had tenderness during an examination.

There are four layers from anterior to posterior separating the exterior vaginal wall from the paraurethral space including epithelium, submucosa, fibromuscular band of smooth muscles, and periurethral fascia. ${ }^{11}$ Paraurethral leiomyoma occurs between the areas in the vesicovaginal septum or paraurethral space. A true paraurethral mass is when it has no connection to the urethra, bladder, or vagina. ${ }^{12}$ Initially in our case due to the anatomical location it was difficult to entitle as the vaginal or the paraurethral mass, following dissection it gave the impression of the paraurethral mass.

USG and MRI may help to estimate the extent, characterization, and involvement of the mass. Egbe, et al. suggested considering the assessment of lactate dehydrogenase (LDH) isoenzyme to differentiate the leiomyosarcoma. ${ }^{2,13}$ However, MRI and LDH assessment were limitations in our context.

Surgical excision is the treatment of choice. In $90 \%$ of cases, the vaginal route is favoured while in $10 \%$ of cases abdominal route is required. ${ }^{3}$ Detailed knowledge on the location of the mass, anatomy of the female urethra, and pelvic structure to facilitate reconstruction and familiarization with varieties of paraurethral, urethral, and vaginal mass is important before surgery. Although we performed surgery gonadotropin-releasing hormone analog and embolization can be used before surgery on the grounds of pathological diagnosis proven by biopsy. ${ }^{14}$

Paraurethtral vaginal leiomyoma is one of the rare kinds which is difficult to diagnose preoperatively. USG aids in identification in location, size of the mass, and its relationship to its adjacent structure. 
Surgical excision via vaginal route is preferred but sound anatomical knowledge is important to facilitate a favourable patient outcome. Definite diagnosis is confirmed following the histopathological report.

\section{ACKNOWLEDGEMENTS}

The authors would like to thank the patient for consenting to her treatment at Karnali Academy of Health Sciences (KAHS) and for this publication.
The authors would also like to acknowledge all the departments and staff for caring for this patient. We would like to thank Dr. Muna Maharjan for her support in editing the article.

Consent: JNMA Case Report Consent Form was signed by the patient and the original article is attached with the patient's chart.

\section{Conflict of Interest: None.}

\section{REFERENCES}

1. Harada K, Ishikawa Y, Fujiwara H, Ishihara G. Female paraurethral leiomyoma successfully excised through a vaginal approach: A case report. J Obstet Gynaecol Res. 2018;44(6):1174-6. [ [PubMed | Full Text | DOI]

2. Sherer DM, Cheung W, Gorelick C, Lee YC, Serur E, Zinn $\mathrm{HL}$, et al. Sonographic and magnetic resonance imaging findings of an isolated vaginal leiomyoma. J Ultrasound Med. 2007;26(10):1453-6. [PubMed | Full Text | DOI]

3. Tramier D, Marinetti C, Jouve MP. Leiomyoma of the vagina: a report on 2 cases. J Gynecol Obs Biol Reprod. 1980;9(3):367-8. [PubMed]

4. Watanabe K, Suzuki T. Uterine leiomyoma versus leiomyosarcoma: A new attempt at differential diagnosis based on their cellular characteristics. Histopathology. 2006;48(5):563-8. [PubMed | Full Text | DOI]

5. Young SB, Rose PG, Reuter KL. Vaginal fibromyomata: two cases with preoperative assessment, resection, and reconstruction. Obs Gynecol. 1991;78(5 Pt 2):972-4. [PubMed | Full Text]

6. Imai A, Furui T, Hatano Y, Suzuki M, Suzuki N, Goshima S. Leiomyoma and rhabdomyoma of the vagina. Vaginal myoma. J Obs Gynaecol. 2008;28(6):563-6. [라bMed | Full $\underline{\text { Text }} \mid \underline{\text { DOI] }}$

7. Ichimura $\mathrm{T}$, Kawamura N, Ito $\mathrm{F}$, Shibata $\mathrm{S}$, Minakuchi $\mathrm{K}$, Tsujimura A, et al. Correlation between the growth of uterine leiomyomata and estrogen and progesterone receptor content in needle biopsy specimens. Fertil Steril. 1998;70(5):967-71. [uㅏMed | Full Text | DOI]
8. De Lima MM, Sampaio CB, Ticianeli JG, De Lima MM, Granja F. Leiomyoma - A rare benign tumor of the female urethra: A case report. J Med Case Rep. 2014;8(1):1-4. . [ [ PubMed | Full Text $\mid \underline{\text { DOI] }}$

9. Leron E, Stanton SL. Vaginal leiomyoma--an imitator of prolapse. Int Urogynecol J Pelvic Floor Dysfunct. 2000;11(3):196-8. [PubMed | DOI]

10. Hye JY, Choi JA, Chung JH, Joo HO, Lee GK, Choi JY, et al. Angioleiomyoma in soft tissue of extremities: MRI findings. Am J Roentgenol. 2009;192(6):291-4. [Full Text | DOI]

11. Dmochowski RR, Ganabathi K, Zimmern PE, Leach GE. Benign Female Periurethral Masses. J Urol. 1994;152(6 Pt 1):1943-51. [PubMed | DOI]

12. Cello V Di, Saltutti C, Mincione GP, Rovereto B, Natali A, Durval A. Paraurethral leiomyoma in women. Eur Urol. 1988;15(3-4):290-3. [PubMed | DOI]

13. Egbe TO, Kobenge FM, Metogo JAM, Manka'a WE, Tolefac PN, Belley-Priso E. Vaginal leiomyoma: Medical imaging and diagnosis in a resource low tertiary hospital: Case report. BMC Womens Health. 2020 Jan;20(1):1-6. [ubMed | Full Text | DOI]

14. Kurokawa S, Kojima Y, Tozawa K, Hayashi Y, Sasaki S, Kohri K. Female paraurethral leiomyoma: immunohistochemical approach to the relationship between leiomyoma and ovarian hormones. J Urol. 2002;167(3):1403-4. [PubMed | $\underline{\text { Full Text }}$ | DOI] are included in the article's Creative Commons license, unless indicated otherwise in the credit line; if the material is not included under the Creative Commons license, users will need to obtain permission from the license holder to reproduce the material. To view a copy of this license, visit http://creativecommons.org/licenses/by/4.0/ 